\title{
BMJ Global Health The care and transport of trauma victims by layperson emergency medical systems: a qualitative study in Delhi, India
}

\author{
Kavi Bhalla (D) , ${ }^{1}$ Veena Sriram (1) , ${ }^{2}$ Radhika Arora, ${ }^{3}$ Richa Ahuja, ${ }^{4}$ \\ Mathew Varghese, ${ }^{5}$ Girish Agrawal, ${ }^{6}$ Geetam Tiwari, ${ }^{4}$ Dinesh Mohan ${ }^{4}$
}

To cite: Bhalla K, Sriram V, Arora $\mathrm{R}$, et al. The care and transport of trauma victims by layperson emergency medical systems: a qualitative study in Delhi, India. BMJ Global Health 2019;4:e01963. doi:10.1136/ bmjgh-2019-001963

Handling editor Stephanie M Topp

Received 4 September 2019 Revised 25 October 2019 Accepted 2 November 2019

Check for updates

(c) Author(s) (or their employer(s)) 2019. Re-use permitted under CC BY-NC. No commercial re-use. See rights and permissions. Published by BMJ

${ }^{1}$ Public Health Sciences, University of Chicago Biological Sciences Division, Chicago, Illinois, USA

${ }^{2}$ Center for Health and the Socia Sciences, University of Chicago, Chicago, Illinois, USA

${ }^{3}$ Independent Researcher, Delhi, India

${ }^{4}$ Indian Institute of Technology Delhi, New Delhi, Delhi, India ${ }^{5}$ St. Stephen's Hospital, Delhi, India

${ }^{6} \mathrm{OP}$ Jindal Global University,

Sonipat, Haryana, India

Correspondence to

Dr Kavi Bhalla;

kavibhalla@gmail.com

\section{ABSTRACT}

Introduction Ambulance-based emergency medical systems (EMS) are expensive and remain rare in lowand middle-income countries, where trauma victims are usually transported to hospital by passing vehicles. Recent developments in transportation network technologies could potentially disrupt this status quo by allowing coordinated emergency response from layperson networks. We sought to understand the barriers to bystander assistance for trauma victims in Delhi, India, and implications for a layperson-EMS. Methods We used qualitative methods to analyse data from 50 interviews with frontline stakeholders (including taxi drivers, medical professionals, legal experts and police), one stakeholder consultation and a review of documents.

Results Respondents noted that most trauma victims in Delhi are rapidly brought to hospital by bystanders, taxis and police. While ambulances are common, they are primarily used for interfacility transfers. Entrenched medico-legal practices result in substantial police presence at the hospital, which is a major source of harassment of good Samaritans and interferes with patient care. Trauma victims are often turned away by for-profit hospitals due to their inability to pay, leading to delays in treatment. Recent policy efforts to circumscribe the role of police and force for-profit hospitals to stabilise patients appear to have been unsuccessful.

Conclusions Existing healthcare and medico-legal practices in India create large systemic impediments to improving trauma outcomes. Until India's ongoing health and transport sector reforms succeed in ensuring that forprofit hospitals reliably provide care, good Samaritans and layperson-EMS providers should take victims with uncertain financial means to public facilities. To avoid difficulties with police, providers of a layperson-EMS would likely need official police sanction and carry visible symbols of their authority to provide emergency transport. Delhi already has several key components of an EMS (including dispatcher coordinated police response, large ambulance fleet) that could be integrated and expanded into a complete system of emergency care.

\section{INTRODUCTION}

In India and many low- and middle-income countries (LMICs), ambulance-based emergency medical systems (EMS) are uncommon.

\section{Key questions}

What is already known?

- Rapid transfer to a medical facility is a key mechanism through which ambulance-based emergency medical systems (EMS) improve trauma outcomes.

What are the new findings?

- Trauma victims are rapidly transported in Delhi, India, to a hospital by bystanders and police.

- India's medico-legal system imposes substantial burdens on good Samaritans by forcing them to interact with police.

- For-profit hospitals often decline to provide first aid and stabilise patients delaying access to care.

What do the new findings imply?

- Formal layperson-EMS should get official sanction from police and carry visible symbols of their authority to assist with emergency transport, and the system should work with empanelled hospitals that have agreed to participate.

- Delhi already has several key EMS components that could be integrated and expanded.

Over half of the global population lives in areas without formal EMS. ${ }^{1-3}$ Victims of traffic crashes in LMICs are typically transported from the crash scene to a hospital by bystanders and passing vehicles. ${ }^{4-12}$ In India, surveillance at medical facilities suggests that most victims are brought to hospital by taxis or police, with ambulances accounting for less than 5\% of transport - a pattern that has shifted little in 30 years (figure 1). Despite strong advocacy, ${ }^{13} 14$ the high equipment and operational costs of ambulance-based EMS suggests they will not be adopted or expanded to scale in many LMICs. ${ }^{1}$

In principle, EMS aim to improve trauma outcomes by providing: (1) medical interventions in the field, and (2) rapid transport to a definitive care facility. However, evidence suggests that many prehospital interventions 


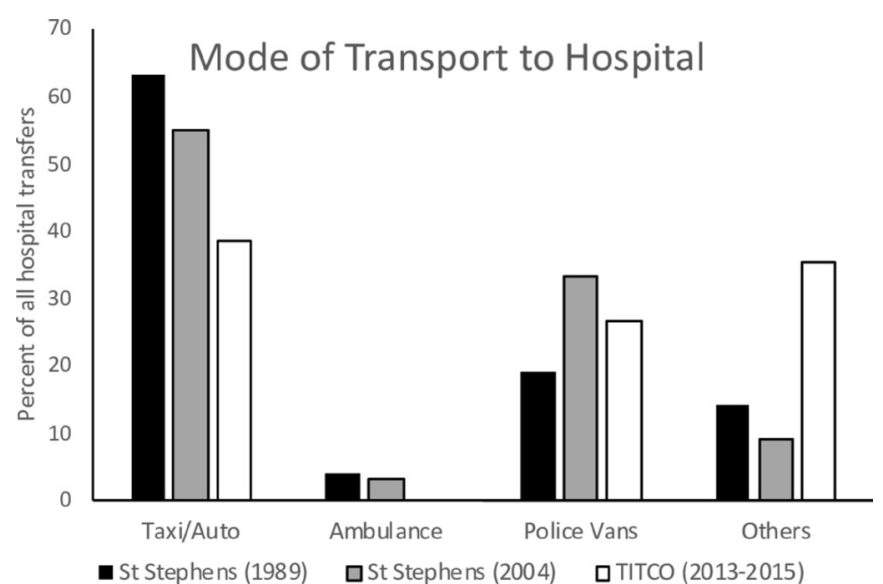

Figure 1 Mode of transport to hospital for victims of traffic crashes in India. ('Others' includes transport by private vehicles, bicycles, cycle rickshaws and other modes. Data sources: St. Stephens Hospital, unpublished data; TITCO: combines data from five major trauma centres in Delhi, Mumbai (two trauma centres), Kolkata and Chennai. ${ }^{42}$ )

are ineffective and that the main benefits of EMS likely accrue from rapid transfer. Increasingly, studies have questioned the benefits of emergency endotracheal intubation, ${ }^{15}$ intravenous drug therapy ${ }^{16}$ fluid resuscitation $^{17} 18$ and spine immobilisation. ${ }^{19-21}$ In fact, studies show that trauma victims transported by advanced life support ambulances have similar or worse outcomes than basic life support, likely due to interventions that are poorly performed and which delay transfer to definitive care. ${ }^{22-26}$ Recognising the weak evidence for advanced training of first responders, the WHO recommends that LMICs should train lay responders, such as commercial drivers, to provide basic first aid and rapid transfer to hospitals. ${ }^{13} 2728$ Several studies have reported training of commercial drivers, police, community leaders and others in LMICs (Ghana, ${ }^{29}$ Madagascar, ${ }^{30} \operatorname{Iraq}^{31} 32$ and Uganda, ${ }^{33}$ among many others $\left.{ }^{12}\right)$.

The second key aspect of EMS - coordination of lay responders to reduce transfer time - has received very little attention in advocacy efforts. Although advanced communication networks have been previously viewed as expensive components of the most advanced systems, ${ }^{3}{ }^{27}$ recent developments in smartphone technology have made coordinated taxi fleets common in LMICs. ${ }^{34}$ In fact, there have been several unsuccessful attempts to develop a 'layperson-EMS' by using peer-to-peer or dispatcher-coordinated networks of lay responders. For instance, in recent years, ridesharing companies in India (Uber in Hyderabad ${ }^{35}$ and Wagon Cab in Delhi ${ }^{36}$ ) have launched emergency ride options. Similarly, some services have attempted to build dispatcher-coordinated networks of existing private ambulances (AMBER Health ${ }^{37}$ and LifeHover ${ }^{38}$ in Delhi, Dial242 in Mumbai, ${ }^{38}$ StanPlus, eSahai and Call Ambulance in $\mathrm{Hyderabad}^{38}$ ). A review of the websites for these services suggest that few have sustained after the initial launch. This indicates that layperson-EMS may face legal, medical and social barriers that need to be systematically addressed.

In 2017, researchers at the University of Chicago and the Indian Institute of Technology (IIT) Delhi initiated a project funded by the US National Institutes of Health to assess the feasibility of developing a coordinated system of lay first-responders that could improve populationlevel outcomes of traffic crashes in Delhi, India. One aspect of the project aimed to understand how trauma victims currently access medical care, and the barriers to such a system being formalised into a coordinated layperson-EMS. In particular, we sought to understand the following aspects from the perspective of frontline stakeholders, policymakers and experts: (i) who helps victims, (ii) how are they transported to hospitals, (iii) what deters help from good Samaritans, (iv) how can these barriers be addressed and (v) could a layperson-EMS improve outcomes. In this paper, we report our findings and share recommendations for EMS policy in Delhi and similar settings.

\section{METHODS}

\section{Study setting and context}

Delhi is the capital of India and has an estimated population of 20 million. It has a complex administrative structure, with federal, state and local government agencies overseeing various aspects of governance. ${ }^{39}$ For example, while Delhi Police is overseen by the federal government, health services are primarily administered by the state government. ${ }^{39}$ Delhi's formal EMS consists of a public ambulance service with a fleet of 265 ambulances (31 Advanced Life Support, 110 Basic Life Support and 124 Patient Transport) ${ }^{40}$ but it is common for emergency transport to be provided by police, taxis (especially auto rickshaws) and private vehicles. ${ }^{41}{ }^{42}$ Healthcare in Delhi is provided by a mix of for-profit hospitals, and relatively low-cost public hospitals. ${ }^{43}$ Patients often leave for-profit hospitals against medical advice for financial reasons. ${ }^{44} 45$ It is standard medico-legal practice across India to treat all injuries as potentially criminal cases that are registered as medico-legal cases and reported to the police. Surveys suggest that the fear of getting entangled in long-drawn legal processes deters bystanders from helping trauma victims. ${ }^{46}$ In 2014, following public interest litigation, the Supreme Court of India instructed the federal government to develop legislation to protect good Samaritans and compel for-profit hospitals to stabilise victims and provide first aid. ${ }^{48}$ Subsequently the government issued an executive order to this effect ('Good Samaritan Notification'). ${ }^{49}$

\section{Study design and methods}

We used qualitative methods to elicit viewpoints of five groups of stakeholders - (1) drivers of taxis (threewheeled auto rickshaws and four-wheeled taxis), (2) medical personnel (doctors, nurses and hospital administrators), (3) legal experts, (4) police personnel and (5) 
1. Crash occurs!

2. Bystander calls $100 *$ reports location

3. Dispatcher uses app to geo-locate crash and notify closest EMS taxi

4. Taxi** driver uses app to navigate to crash using quickest path through traffic

5. At scene: taxi driver manages crash scene, provides first-aid, safely loads victim

6. Taxi driver use app to navigate to closest designated hospital using quickest path

7. At hospital: taxi driver delivers victim; uses app to report summary crash data

8. App automatically de posits payment through mobile-to-mobile transfer

Notes:

* The proposed app is not for use by the general public, who will call the existing emergency contact number (100) in Delhi, where a dispatcher will decide if a taxi should be sent to the crash site. Instead, the app is intended for taxi drivers who are participating in the system.

** "Taxi": Here, and throughout this document, we use the word taxi to include both 3-wheeled taxis (autorickshaws) and 4-wheeled taxis. However, the distinction between the two modes is important for this study and where needed we differentiate between the two.

Figure 2 Process flow of the proposed dispatcher coordinated taxi-based EMS. app, application; EMS, emergencymedical systems.

other stakeholders (including policymakers, ambulance providers, non-governmental organisations (NGOs), hospital stretcher bearers and security guards and public health researchers). We acquired research data through:

\section{Key informant interviews}

\section{Sampling}

We used a combination of purposeful sampling techniques. ${ }^{50}$ All respondents had experience with transport, medical or legal aspects of trauma either as professional practitioners or through policy engagement (criterion sampling). We relied on recommendations from interviewees to identify additional respondents (snowball sampling), and used convenience sampling to identify certain taxi drivers and medical personnel.

\section{Interview guides}

We designed interview guides to understand respondents' experiences and viewpoints towards emergency transport, barriers to bystander assistance and a coordinated layperson-EMS (figure 2). The guides were informed by preliminary discussions with a sample of stakeholders prior to data collection. We refined and added questions as data collection progressed. Interview guides are provided as online supplementary appendix A1.

In order to anchor reactions about a coordinated layperson-EMS, we presented respondents with a hypothetical taxi-EMS (figure 2) consisting of a fleet of taxis with drivers trained in first aid and dispatchercoordinated using a smartphone application (app). When an emergency call is received at the control room and no ambulance is available, the taxi closest to the crash site is recruited through the app. The app provides navigation to the crash site and the closest participating hospital, where the driver is paid for their effort using mobile-to-mobile cash transfer.

\section{Data collection}

Four researchers (RA, RAr, KB, VS) with backgrounds in transportation, engineering and/or public health collected data during December 2017 to March 2019. Two researchers had training in qualitative methods (VS, RAr), while one underwent a short training in qualitative methods before the project began (RA). We conducted 50 interviews (26 recorded), typically lasting 45 to $60 \mathrm{~min}$, in Hindi, English or a combination (table 1). These included five short interviews ( $<15$ mins) with individuals with knowledge about a specific topic but who were not suitable for full length interviews. We took handwritten notes, which were typed and stored electronically.

Stakeholder consultation: Halfway through data collection (June 2018), we held a stakeholder workshop to share emerging ideas and get feedback. The workshop had 16 external participants (table 1 ) in addition to seven from our team, and included legal experts, academic researchers, government bureaucrats, ambulance administrators, physicians and senior police personnel. We took notes which informed our data collection and analysis.

Document review: Thirty-six documents were reviewed to gather information on legal judgements, national and state policies and operational procedures. Documents were identified through internet searches and discussions with participants.

\section{Analysis}

Drawing on principles from general thematic analysis, ${ }^{51}$ recorded interviews were transcribed by a contracted transcriber, and cleaned and checked by a team member (RA). We combined deductive and inductive approaches in the process of developing the codebook, using some predefined codes and allowing others to emerge during coding. We first applied the draft codebook to three transcripts, and further refined the codes. Next, two of the four coders (RA, RAr, VS, KB) coded all transcripts and notes. We consolidated our coding in NVivo and partitioned the data. Team members reviewed the coded data and developed early themes. Two members (KB, VS) further refined the themes, and finalised them after discussion with the entire research team.

\section{Data quality}

We strengthened data quality by: (1) Triangulation - we discussed concepts across stakeholder categories and cross-checked respondent statements with key documents; (2) Prolonged engagement - we spent 14 months collecting data at regular intervals, allowing us to develop a deeper understanding of the topics; (3) Peer debriefing - we had regular group meetings throughout the research process and (4) Respondent validation through a stakeholder consultation.

\section{Reflexivity}

Our study was underpinned by a constructivist epistemology, where our goal was to capture the perspective of respondents, many of whom held different viewpoints. However, we also attempted to gain a positivist understanding of relevant processes. The research team was multidisciplinary, and we had regular discussions on epistemological approaches and the impact of these different approaches on data collection and interpretation.

\section{Patient and public involvement}

We did not involve patients in the development of the research question. A stakeholder consultation midway 
Table 1 Data sources: interviews, stakeholder consultations and documents

\begin{tabular}{|c|c|c|}
\hline Type of interviewees & Interviews & Details \\
\hline Legal experts & 5 & Incl. four that participate in policy dialogue* \\
\hline Medical practitioners & $16 \dagger$ & $\begin{array}{l}\text { Incl. } 11 \text { doctors, three nurses, one hospital administrator and two EMTs; nine from } \\
\text { government hospitals, two from a charitable private hospital and five from for-profit } \\
\text { private hospitals; five participate in policy dialogue }\end{array}$ \\
\hline Police personnel & $8+$ & $\begin{array}{l}\text { Incl. three that participate in collecting evidence used in accident claims tribunals; } \\
\text { two senior police officials; one police control room van driver, one from a public } \\
\text { hospital police post; two participate in policy dialogue }\end{array}$ \\
\hline Taxi drivers & 10 & $\begin{array}{l}\text { Incl. eight auto rickshaw drivers, two that drive both auto rickshaws and four- } \\
\text { wheeled taxis and one Uber driver }\end{array}$ \\
\hline Other stakeholders & 11 & $\begin{array}{l}\text { Incl. two academic researchers, two policymakers, two NGO representatives, } \\
\text { two ER stretcher bearers, two ER security guards and one public ambulance } \\
\text { administrator }\end{array}$ \\
\hline
\end{tabular}

EMTs, emergency medical technicians; ER, emergency room; Incl., including; NGO, non-governmental organisation.

\begin{tabular}{lll}
\hline Stakeholder meeting & Participants & Details \\
\hline Meeting & 23 & $\begin{array}{l}\text { Including five legal experts, seven academic researchers, three government } \\
\text { bureaucrats, one ambulance administrator, four trauma physicians and one senior } \\
\text { police personnel }\end{array}$ \\
\hline Document review & Documents & Details \\
\hline Documents & 36 & $\begin{array}{l}\text { Including three legal judgements, five laws and regulations, eight online articles } \\
\text { and news stories, six monographs and academic articles, nine policy briefs and } \\
\text { agency reports. }\end{array}$ \\
\hline
\end{tabular}

*Individuals who participate in policy dialogue related with emergency medical response, trauma care and good Samaritan protections. †Including short interviews with one medical practitioner and four police personnel.

through the study was used to share emerging findings, get feedback and refine interview questions, and inform analysis. Findings will be disseminated at opportune district and national meetings.

\section{RESULTS}

We start by presenting themes related with what happens at the scene, and at the hospital, where we focus particularly on medico-legal practices and inter-hospital transfers, which emerged as the primary deterrents to help from good Samaritans and a source of delays in access to medical care. Finally, we present themes related with strengthening the system of prehospital transport and care in Delhi. Boxes 1-4 present selected quotes organised by thematic headings.

\section{At the crash scene}

Crowd behaviour: Respondents commonly noted that large crowds usually gather at crash scenes. While most people are primarily onlookers, many respondents noted that usually someone steps forth to manage the situation and/or help the victim. Such help includes calling the police, persuading drivers of passing vehicles drivers to transport the victim to a hospital, and contacting family members using information obtained from the victim or their belongings.

Modes of transport: Many respondents asserted that police vans and auto rickshaws are the vehicles most commonly used for transport, with police vans being used more for victims with extensive visible trauma.

Police will be called first if the condition is very serious but sometimes what happens is a person is transported in auto and he dies on the way, then it will be asked that why haven't you called at $100 \ldots$ therefore first of all police should be called. TD8

Many respondents described the police as providing a de facto EMS for trauma. Senior police officers explained that Delhi Police started using Police Control Room vans equipped with stretchers and first aid supplies, and training patrol staff in first aid, starting in the 1980s. This infrastructure was eventually expanded and integrated into routine police operations. Many respondents strongly perceived that the Delhi Police operate a robust system with a widely known number (100), large fleet of vehicles and rapid response. Respondents familiar with other Indian cities observed that such coordinated use of police for emergency transport is unique to Delhi.

Some respondents noted that public and private ambulances are common in Delhi but are used primarily for inter-hospital transfers. Some added that public awareness of public ambulances is growing and bystanders increasingly also call their number (102), but many noted that police vans arrive on the scene much sooner and transport victims without waiting for the ambulance. 
Box 1 Selected quotes related with what happens at the crash scene

\section{At the crash scene \\ CROWD BEHAVIOUR AT SCENE}

- 'it's mostly police and to some extent there are some you know bystanders who will help. It is also seen that the auto rickshaw drivers or the taxi drivers they help more than the normal general public.' MP3

- 'sometimes the situation becomes worst ... public start beating the driver. Sometimes their family members arrive. Patient is serious, bleeding too much, their relative does not bear after seeing this ... The Gujjar, Jatt, of Delhi do not talk, they start beating ... These people are well educated so start beating us.' TD9

\section{MODES OF TRANSPORT}

- $40 \%$ to $50 \%$ (of trauma cases) are brought still by the police. Right? Rest are being brought by bystanders or relatives ... other common modes of private transport or auto rickshaws which are very common, three wheeler auto rickshaws, taxis and then private four wheelers or private two wheelers also in fact, motorised two wheelers. Only about $3 \%$ to $5 \%$... are being brought in by the CATS ambulance services.' MP16

- 'I will say in Delhi, in the most cases PCR van, this is the reality, that lots of time passersby ignores, ambulance also do not reach, hospitals do not send but in $90 \%$ cases police's PCR van transport him to the hospital.' PP1

\section{CHOICE OF HOSPITAL}

- 'we do not feel courage to take him to the private hospital as we are unaware of his situation and who will pay for it. In private hospitals money has to be deposited before the treatment. And for the unknown I will transport to the public hospital because how will I pay, I can't afford it.' TD5

MEDICAL CONCERNS WITH LAYPERSON TRANSPORT

- '... ambulances are used as a transport vehicle. ... even in USA when there are highly trained paramedics, they are not supposed to do lot of interventions on the scene because that can harm the patient. So ultimately the primary objective is that patient reaches the definitive care facility as quickly as possible.' MP11

- 'Autos are not the ideal mode of transport because you can't make the patient lie down flat on the back ... but you know in our condition I think that is even better because rather than no transport the patient lies on the roadside bleeding to death which happens so many times over here. I think even if they just pick up the guy and bring I think it is great job done.' MP13

- '... the liability of the auto rickshaw driver for causing further damage is not addressed by the law. ... And if it has been raised somewhere, they might have beaten up the auto rickshaw driver, and that is all. But it has not been raised as a legal issue in a court of law.' LE1

CATS, Centralised Accident and Trauma Services; LE, legal expert; MP, medical practitioner; PCR, Police Control Room; PP, police personnel; TD, taxi driver.

...one must be aware of the ambulance number but I don't know ... (we know that) if you call 100 number police vehicle will come transport. TD4

Taxi drivers (TD) cited humanitarian and spiritual reasons, as motivating factors for helping ('as we are sowing so shall we reap later.'TD4) but some noted that taxi drivers may be persuaded by bystanders or police to help. Police personnel noted, and two taxi drivers confirmed,
Box 2 Selected quotes related with what happens at the hospital

At the hospital

MEDICO-LEGAL PROCESSES

- 'Policemen say you sit inside let him become conscious, you go after that. That's why the auto drivers hesitate even more.' TD1

- 'The police might want to settle the matter - take a certain amount from each party and close the case.' LE4

- 'The image of the police, and its practices, are such that people do not want to get caught in a situation where the police might extort money from them and harass them just because they helped the victim.' Stakeholder Consultation

- '... they feel there would be problems related to police case, it is a medico-legal case, .... Sometimes they want to help but they are more concerned about their own safety and not get entangled to the unnecessary problems.' MP11

- '(Medico-legal process) doesn't happen over here because it is a very cumbersome process and we can't afford to waste our time getting into those legalities. So we always prefer if patients, they are referred back to us, ... So we don't get involved in those formalities directly.' MP13, doctor at private hospital

- 'It is my personal view that if we are helping someone our job is only to drop him to hospital and handover him to the hospital staff and after that we are free to leave. If this happens then all will help.' 0S7, stretcher bearer

- 'as medical professional we find it distressing to have the police in the ER.' Stakeholder Consultation

- 'if they are put down as a witness, then they would be required ... to appear and provide evidence. ... That is what keeps them away from taking a patient to the hospital. ... I wouldn't, for instance, if I was a lawyer or a businessman, take somebody in my car, if I fear that I might have to go to court half-a-dozen times.' LE1

INTER-HOSPITAL TRANSFERS

- 'I think it is fairly common from private hospitals to be referred to government hospitals and one major reason is not the expertise, because expertise may be available in these private hospitals ... lot of trauma patients are transferred because they cannot afford the treatment in private facilities.' MP11

- 'We usually don't refer. Most people leave against medical advice after stabilisation sometimes for financial reasons etc after stabilisation. There is zero charge for stabilisation.' MP12; doctor; private hospital

- 'Private hospitals are very clever. They know the provision. They will give you first aid and then ask you to deposit 50000 rupees for further treatment or take him away. And you can't do anything. ... There have been two to three times cases where they (private hospitals) did refuse to give the body of the deceased to the family until and unless they deposit the expenses. ... after giving the first aid and some treatment they will ask the patient to deposit the money otherwise they will ask him to take the patient away. ... They (private hospitals) will just admit him and that's all, rest depends on the patient. He has to bring the money for depositing, if he doesn't on some pretext or the other the hospital refuse to admit him.' LE5 LOGISTICAL AND OTHER PROBLEMS

- 'I am transporting him but who will go with him? ... Because we face this major problem in hospital that either we ... should carry the injured person on stretcher or should park my three-wheeler in parking. If I will go to parking then 10 to $15 \mathrm{~min}$ would be waste for sure. Parking is not nearby.' TD5

Continued 


\section{Box 2 Continued}

- 'These days in (hospitals) five to six bouncers are posted for the safety of doctors that no one attacks them. When (the doctors/nurses) are sitting and gossiping, not helping anyone, then what will one do? ... will you not feel angry? Yes or no? ... If you want to do the real study then go to Safdarjung and see, the female is pregnant and in trouble but no doctor is helping her, four to six doctors, ladies are sitting and gossiping there ... Many times the doctors and female doctors are beaten up by the public, why did they beat them? Because what they do is just sit and gossip.' TD7

LE,legal expert; MP, medical practitioner; OS, other stakeholder; TD, taxidriver.

that police sometimes pay taxi drivers to transport crash victims. Compared with four-wheeled taxis, respondents noted that auto rickshaw drivers helped more often because they are ubiquitously available, easier to accost and easier to clean if soiled by blood and bodily fluids.

Choice of hospital: Most respondents agreed that the choice of hospital is determined by victims or their companions if they are alert, and the decision includes considerations of injury severity, ability to pay, types of facilities in the vicinity and where they know a doctor. If they are unable to decide, bystanders make the choice based on similar considerations. Taxi drivers predominantly preferred public hospitals and noted that despite

Box 3 Selected quotes related with the effects of new legal protections for good samaritans

\section{Effects of new legal protections for good samaritans}

- 'It is the duty of the hospitals to actually proclaim in big bold letters that have no fear, bring the injured here, so it's their duty in law. They are not doing it.' LE2

- 'how much impact that has made after about 2 years? ... I don't think it has got big impact ... it has not drastically changed the pattern of people who are bringing in patients to be very frank.' MP16

- 'earlier, it was such that if there was an accident, 'What if we only get caught?' People used to get scared. But now, it is not like that ... Now, the laws have ... changed. Because of that, they help.' MP1

- 'the police chowki (post) guy will ask for name/number. While the Supreme Court says that you do not need to give your information, these people will still ask.' LE4

- 'As far as awareness (of legal protections for good Samaritans) is concerned is minimal in the last 1 year we have trained about 3500 police officers across 10 states. Not a single one of them knew about this. So it is a huge uphill task to ... let the police and other authorities know that they now have some obligations and duties towards the good Samaritan ... the awareness level is still quite low and for us that reveals a big challenge in terms of implementation of the law.' $0 \mathrm{~S} 5, \mathrm{NGO}$ representative

- 'Yes they do have to appear before the court and they will even after the good Samaritan law comes in. They will be cited as witnesses.' LE2

LE,legal expert; MP, medical practitioner; NG0, non-governmental organisation; OS, other stakeholder.
Box 4 Selected quotes related with recommendations for improving the system

\section{Recommendations for improving the system}

- 'we are worried about duplication, we're talking about integration. We do not want any new numbers. ... One number that works for all emergencies.' Policymaker, Stakeholder Consultation

- 'if they (taxis) become part of the umbrella then obviously you can have any amount of ferrying vehicles ... control room knows that ok if there is not an ambulance but there is a taxi ... they will definitely improve the response time.' MP16

- 'if I phone and say my son has swallowed a marble, can you refuse? It's unethical to have a system only for road traffic injuries (RTIs).' Academic, Stakeholder Consultation

- '(ambulances) are preferred, but if they take time to reach, it is better that the patient be shifted to the hospital as quickly as possible in any available vehicle.' MP1

- 'If we should encourage a structured system of transport (by autos/ taxis) then it should be done properly. Whether it is a neck or back injury, an auto will be impossible to fit a person in. Maybe in a taxi.. especially one like a PCR - with a length-wise seat. Spine stability is important.' MP12; doctor; private hospital

- 'Taxi is much better than auto. It has more space, jerking movements are also less.' MP7

- 'They should be trained, so they do not harm the patient during the transport and they know about the hospitals and the facility.' MP10

- 'If he (auto rickshaw driver) has an identity card, then he won't be stopped at all. Without an ID card the cops will stop and ask whether he (auto rickshaw driver) hit the injured.' PP5

- 'People don't mind giving their time for a cause ... They should be incentivised. ... But not too much.' MP5

MP, medical practitioner; PP, police personnel; RTIs, road traffic injuries

the law and government assurances, for-profit hospitals don't initiate care without a guarantee of payment.

In private hospitals money has to be deposited before the treatment. And for the unknown I will transport to the public hospital because how will I pay (at a private hospital). TD5

Police typically transport victims to one of Delhi's nine designated public trauma centres unless the victim or their companions request otherwise, or in exceptional circumstances, such as a particularly severe crash that occurs near a major for-profit hospital.

Medical concerns with layperson transport: Many respondents raised concerns with the use of auto rickshaws for emergency transport. Medical respondents often stated that laypersons can exacerbate neck and spine injuries. Some noted that auto rickshaws have a jerky motion and are not wide enough to accommodate supine patients, arguing that emergency transport should be provided by equipped ambulances and trained providers.

... in auto space is very less. Patient's leg will get folded, hand will get fractured, neck will also get tilted. MP6; nurse

However, when further probed, they usually added that despite such concerns they had never received a patient 
whose injuries were worsened because of transport by auto rickshaw.

... the patient gets an injury, and by the time they get here, it is worse because of the movement ... But in my shift, none like that have come. MP1; nurse

Such objections were more often raised by nonmedical professionals or junior medical professionals. Senior medical respondents and/or those who participate in policy dialogue on EMS raised such concerns less frequently, and when they did, usually noted that the benefits of rapid response by laypersons outweighed the potential of exacerbating injuries. Two senior medical respondents also noted that in practice even ambulance crew do not take adequate spinal precautions.

\section{At the hospital}

On arrival at the casualty or emergency department (ED) entrance, patients are transferred to stretchers and wheeled in, where they are triaged and directed to diagnostic services or treatment. Two processes of registration, medical and medico-legal, start nearly simultaneously with medical care.

\section{Medico-legal processes}

Most major public hospitals have a police post, where a message is sent from the ED requesting the medicolegal register. Smaller public hospitals and private hospitals that do not have a police post maintain a medicolegal register, and hospital security contacts police when a medico-legal case is received. The doctor who first examined the patient fills the medico-legal form, documenting the event time, date, location (which determines police jurisdiction) and a medical description of injuries. Medico-legal registration is a starting point for police involvement, which almost all respondents noted is a deterrent to bystander assistance and medical care.

\section{Police presence in hospitals}

Medico-legal processes result in a high-level of police presence in the hospital. We observed that police posts at major public hospitals were usually a busy site. Typical activities included police officers questioning companions of victims to determine crash location, making calls to police stations with jurisdiction to initiate investigations, obtaining contact information of witnesses and recording statements and overseeing the medico-legal register. We also observed substantial police presence at the ED, especially in the ambulance bay, the triage area and at the bedside. Here, in addition to obtaining testimony, police were helping negotiate settlements.

the police come between the person who has hit and who has been hit and then they negotiate. They will tell this ...

'ok I will leave you if you give me this much. MP16

If the parties don't settle, the victim, or their representative, registers a 'First Information Report' (FIR), which officially initiates a police investigation, and legal proceedings that can last years.
The major concern is that (it) would require them to make several journeys as witnesses to the trial courts, (which) are notorious for being ... slow ... courts and hospitals are two places where Indians don't want to go. LE2

Police respondents claimed that such negotiations are for cases involving mild injuries and that serious cases are 'cognisable' (ie, police officer has the authority to independently initiate an investigation) and are always investigated. However, other respondents noted that even serious injuries are settled with police mediation but carry the risk that the offending party may renege. Therefore, victims often wait for 10 to 15 days to confirm payment before asking the police to file an FIR.

Several medical respondents noted that police presence is distressing to patients and medical staff and interferes with medical care. Further, they stated that medico-legal registration and testifying in court adds a substantial burden on doctors. (If an FIR is filed then the court will call the doctor ... It is definitely burdensome but we have to oblige.' MP2) They cited this as a reason why some doctors and private facilities avoid engaging with medicolegal cases.

\section{Harassment of good samaritans}

Forced interactions with police and subsequent visits to court were the most commonly cited reason that deterred people from transporting crash victims to hospital.

Police will call you, ask you, who, what, why ... you would be called in police station again and again. TD5

In addition to describing police interactions as unpleasant, respondents often pointed to more serious concerns. Taxi drivers, legal experts (LEs) and some other respondents commonly talked about good Samaritans being wrongly accused, and sometimes convicted, of causing the crash. Anecdotes from taxi drivers commonly included being unwillingly held at the hospital until the victim regained consciousness and absolved them of responsibility ('Policemen say you sit inside, let him become conscious, you go after that.' TD8). Many talked about police intentionally accusing innocent bystanders in an attempt to extort money, or because they had received bribes from the guilty party. Several respondents noted that police try to coerce dishonest testimony or rely on professional witnesses and close cases quickly. For example, one lawyer with experience in handling such cases indicated that victims are sometimes coerced to implicate bystanders, and that 'professional eyewitnesses' who provide false testimony are common.

The police were not the only source of such harassment. Taxi drivers talked about doctors and nurses persuading them to share their contact information, which two nurses corroborated.

... giving a contact number is not a big deal. We try to convince him. MP7, nurse 


\section{Inter-hospital transfers}

Medical and non-medical respondents talked extensively about patients being shunted between hospitals, leading to delays in medical care. Among the common reasons for transfers from public hospitals and small private hospitals was the absence of medical specialists, unavailability of beds and/or lack of medical services. For major for-profit hospitals that typically have the facilities and expertise to provide care, inability to pay was the most common reason. Respondents mentioned that often patients remain at private hospitals until they have exhausted their resources before moving the patient to a public facility.

referrals come from hospitals which are corporate or private hospitals, and patients when they exhaust their money, when their financial situation becomes very bad, they come to us. MP9; public hospital

Some respondents noted that some hospitals violate the law by refusing to release the dead body, or retaining property (such as vehicles) until payments are made.

Several respondents, including one from a private hospital, mentioned that private hospitals prefer not to accept trauma cases brought directly from the field to avoid medico-legal processes. Instead, some private hospitals encourage patients to go to a public hospital for medico-legal registration before returning for medical care.

Most respondents mentioned that private hospitals are required by law to stabilise patients and provide first aid. However, many argued that for-profit hospitals would not be financially viable unless they charged for such services.

ultimately they are private hospitals. They run for profit. MP16

One respondent noted that for-profit hospitals have security guards at the gate that informally advise taking the patient to other public facilities. Others mentioned that in cases where the victim is seen by a medical professional, they often receive inadequate care because stabilisation, resuscitation and first aid are poorly defined concepts. A few respondents from public hospitals described instances where the condition of the patient worsened because they were transferred without being stabilised. Many noted that inter-hospital transfers occur without any communication leaving the receiving hospital ill-prepared to respond.

\section{Logistical and other problems}

Several taxi drivers mentioned loss of work hours as a problem if they help take a victim to hospital. Many also raised other issues, especially parking. Unlike ambulances, which can be left unattended at the ED entrance, private vehicles have to park in the visitor's parking lot, which may be some distance and require parking fees. Importantly, taxi drivers mentioned (and we observed) that patient companions play an important role in unloading the patient from transporting vehicles, pushing the stretcher in the hospital and, more generally, advocating for resources (eg, medical attention, hospital beds, access to imaging services). Taxi drivers are unable to play this role while they are looking for parking. Many taxi drivers noted that they are much more willing to transport crash victims if there is an accompanying person.

Beyond forced interactions with police, taxi drivers and other respondents also pointed to other forms of harassment at the hospital. Some mentioned hostile questioning by doctors and medical staff ('Who are you? From where have you come? They ask like this...'TD10), and, in some instances, being assaulted by agitated family members when they arrive at the hospital. ('Sometime their family members arrive, and the patient is serious, bleeding too much, their relative does not bear after seeing this ... they start beating us.' TD9). More generally, EDs were described by some as unpleasant environments. Respondents described incidents of violence at the ED, often directed at hospital staff who are perceived as not doing enough for patients, but sometimes also directed at good Samaritans who bring patients to hospitals. Our observations at the EDs showed numerous means for managing such violence, such as limited entry points, lots of security guards, signs that prohibited some items that can be used as weapons and heavily fortified doors and windows.

\section{Effects of new legal protections for good samaritans}

The government's recent Good Samaritan Notification instructed police and hospitals to protect good Samaritans, and ensure that private hospitals provide critical care. ${ }^{49}$ However, our respondents stated conflicting opinions about whether the Notification had affected practices. Although several mentioned that good Samaritans were no longer detained at hospitals, or forced to provide their contact information, many respondents said that practices perceived as harassment remained unchanged. This was usually attributed to a lack of awareness of the new legal protections. However, legal respondents who participate in court proceedings noted that the Notification was unlikely to help because police practices that are perceived as harassment have always been unlawful. In particular, they noted that the law has always been interested only in the testimony of witnesses, and the Notification doesn't change this. Detaining non-witnesses and coercing testimony has always been unlawful. Nevertheless, most respondents agreed that the Notification has positive features, such as limiting how often witnesses and medical professionals are required to testify in court. The Notification also requires hospitals to post signs highlighting legal protections for good Samaritans but, consistent with our observations, respondents said that it was very rare for hospitals to post such signage.

We had put up a noticeboard saying that nobody had to give their name but we have removed. ... maybe because of some renovation. MP2; doctor; private charitable hospital

The Notification also emphasised a previous Supreme Court ruling that compels all hospitals to stabilise crash 
victims and provide first aid but many respondents noted that hospital practices were unchanged. Respondents noted that the problem is unlikely to be fixed unless financial mechanisms are created to reimburse private hospitals for the costs of providing care. They described several attempts by state governments to create cashless insurance systems and current attempts by the federal government to establish universal health coverage that may help.

\section{Recommendations for improving prehospital care and transport in Delhi}

Almost all respondents agreed that lay responders had an important role in transporting trauma victims to hospital especially since it is already common practice. However, a few cautioned against inadvertently doing harm to the current system of police-based transport in Delhi. Most respondents emphasised that attempts at strengthening prehospital care should be part of a coordinated system of emergency response. The following issues consistently emerged in our interviews.

- Single call number: Many respondents commented on the proliferation of emergency numbers (fire, police, ambulance, women safety, etc) and the need for a single nationwide number.

- Responding to all emergencies: Some respondents noted that an EMS should respond to all emergencies because restricting to specific causes (eg, accidents) is not ethically justified.

- Include private ambulances: Some respondents recommended integrating private ambulances into the coordinated EMS. Private ambulances for interhospital transfers are common in Delhi.

- Use of appropriate transport modes based on injury severity: Most respondents felt that taxis were appropriate for minor injuries but diverged in their views about severely injured victims, which many felt should be handled by paramedics and ambulances.

- Importance of rapid transfer to hospital: Many senior respondents commented on the trade-off between providing medical care in a prehospital setting and in rapid transport. Most agreed that since it is difficult to provide advanced interventions in the field, victims should be transferred to hospital by whatever means available.

- First aid training: All respondents noted the importance of training of first responders (lay or professional).

- Appropriate financial compensation: On the issue of monetary incentives for lay responders (such as taxi drivers), all taxi drivers felt that they should be compensated for their time. Other respondents took more nuanced positions. Many felt that public recognition is the most important incentive, and that monetary rewards should be carefully calibrated to not create perverse incentives. Some felt that monetary rewards shouldn't be offered at all. Respondents also noted that the new policy of the Delhi government to give rupees $2000(\sim \$ 30)$ to anybody who transports a crash victim to hospital is unlikely to work unless there are real protections for good Samaritans. Medical respondents noted that so far, the reward is rarely claimed.

- Managing EMS costs: Respondents who participate in policy dialogue pointed to the high cost of ambulances and the savings expected from using lay responders. Cost issues weren't raised by other respondents.

- Mechanisms to give legitimacy to lay responders: Some respondents alluded to class perceptions, asking if victims, families, bystanders and police would trust taxi drivers to behave responsibly. ('the first thing is trust development ... between the taxi drivers and the victim because ... pregnant victims and ... ladies ... don't enjoy much of a trust with taxi drivers' MP9). They suggested that participating drivers should carry visible symbols (eg, badges, medallions, certificates) of their association with the EMS. Several respondents noted that such legitimacy should be sanctioned by police and the medical system, and provide participating taxi drivers with several privileges, including leaving their vehicles unattended in the ambulance bay, and not being coerced into sharing contact information, providing statements or being identified as witnesses. Although such issues related with establishing trust and legitimacy were not raised by taxi drivers, their responses suggested that they assumed that their participation in a taxi-EMS would confer protections from harassment. We asked all interviewed taxi drivers if they would be willing to participate in such a system. All agreed, often with enthusiasm.

- Legal feasibility of a taxi-EMS: We asked legal experts and policymakers if they expected the drivers of a purpose-built taxi-EMS to have legal protections intended for good Samaritans. Respondents agreed they would because participation was voluntary. They agreed that the tort liability of those who help has never been raised in the courts in India but one respondent added that if the taxi-EMS is legally challenged, it is possible that some forms of transport, such as auto rickshaws, may not be viewed as appropriate by the judiciary.

\section{DISCUSSION}

India is in the midst of making substantial changes to national health and transportation policies, ${ }^{52}{ }^{53}$ and improving trauma outcomes is the focus of significant policy dialogue. In the last few years, there has been extensive advocacy from NGOs, ${ }^{47}$ Supreme Court judgements, ${ }^{48}$ executive orders ${ }^{49}{ }^{54}$ and substantial national and international news coverage focused on improving access to care for trauma victims. ${ }^{556}$ Our study provides important insights relevant to this dialogue by providing a rich description of what happens to trauma victims in the field, at hospitals and in the medico-legal system. In the discussion that follows we highlight key legal, medical 
and social issues, focusing specially on implications for a layperson-EMS.

\section{Addressing legal barriers}

In India, deeply entrenched medico-legal practices force good Samaritans into extended and often onerous interactions with police. Surveys suggest that over half of law-abiding Indian citizens fear the police ${ }^{57}$ and our results illustrate why. Our respondents shared many anecdotes where good Samaritans were coerced into being witnesses, held against their will or much worse, wrongfully implicated in causing the crash. Furthermore, medical professionals dislike adhering with medico-legal practices because they interfere with patient care.

India's recent Good Samaritan Notification ${ }^{49}$ tries to circumscribe allowable police practices but our findings suggest that the Notification appears not to have affected medico-legal processes substantively. This is likely because the executive order doesn't stop police from questioning witnesses, and the most irksome police practices, such as coercing testimony, were already illegal. The Notification also instructs local governments to give rewards to bystanders, which pale in comparison to the medico-legal burdens. This may explain why only $4 \%$ of good Samaritans who helped trauma victims have claimed the financial incentive of rupees $2000(\sim 30)$ being offered by the Delhi government. ${ }^{15}$

While WHO recommends that countries establish legislations that protect good Samaritans, ${ }^{13}$ our study highlights that the issues and legal remedies will likely vary based on country-specific conditions. Globally, good Samaritan laws are typically framed as either duty-to-assist or protection-against-liability, ${ }^{58}$ which may not make sense in many LMICs. Consider, for instance, that good Samaritan laws in the USA successfully helped alleviate physician concerns that they would be sued for malpractice if they helped at accident sites. ${ }^{59}$ However, China's new law protecting good Samaritans from the liability of exacerbating injuries fails to address their main concern of being implicated of causing the accident. ${ }^{6061}$ Thus, it is important that LMICs assess their particular situations and evolve appropriate countermeasures for protecting good Samaritans. For our specific example, protecting taxi drivers against police harassment would likely require the taxi-EMS to have official police sanction, and the taxis to carry visible symbols (eg, medallions or certificates) of their authority to provide emergency transport.

\section{Addressing healthcare system barriers}

Although a layperson-EMS aims to address transportation barriers, our findings highlight other important sources of delays in India's healthcare system. Notably, care at forprofit hospitals is often delayed until it is established that somebody will pay for victims who may be poor, unaccompanied and/or disoriented. Although an amendment to the Motor Vehicles Act has required all hospitals to stabilise patients since $1994,{ }^{62}$ our respondents described many anecdotes of how for-profit hospitals sidestep requirements. Such practices will likely continue until there is a mechanism for hospitals to recoup costs, such as through no-fault universal health coverage, as recommended by the Sustainable Development Goals. ${ }^{63}$ India is in the midst of major legislative and policy reforms to its healthcare ${ }^{4352}$ and motor vehicle insurance sectors, ${ }^{53}$ whose implementation could create such a financial mechanism. However, until it is established that for-profit hospitals reliably provide care, good Samaritans should take victims with uncertain financial means to public hospitals. For a layperson-EMS, this likely means transporting to hospitals that have agreed to participate and have the requisite capacity.

\section{Addressing social barriers}

Our findings suggest that a layperson-EMS could face opposition from various stakeholders. The underlying rationale for a layperson-EMS is that rapid transfer to hospital is of overriding importance for improving outcomes. Although our senior medical respondents understood this well, junior medical respondents commonly expressed concern about exacerbating spinal injuries. Similar apprehensions were also raised by some of our non-medical respondents. Although such concerns are likely overstated, ${ }^{19-21}$ the social acceptability of a layperson-EMS will likely require its medical legitimacy to be accepted by the public.

Social class issues were the subtext of many reactions to our proposed taxi-EMS. Often these took the form of a strong bias against the vehicle (especially auto rickshaws) and the entrenched class hierarchies of cities such as Delhi, but also concern of whether taxi drivers were responsible actors who would be trusted by, for instance, pregnant women. Regardless of whether such apprehensions have merit, ensuring social acceptability of a taxi-EMS may require that the system is viewed as a semiprofessional operation with visible symbols of authority to act in an emergency, and with trained drivers who appear to be following a prescribed protocol.

\section{Building a complete system of emergency care}

Our study finds that Delhi already has key EMS components that could potentially be integrated and expanded into a complete system of emergency care. Notably, our study highlighted that the police in Delhi already transports trauma victims to hospital as a routine part of operations. In effect, they respond to accidents like a coordinated non-medical EMS, with a control room and dispatch protocols, fleet of vehicles equipped with first aid and victim transport capabilities, providers with rudimentary training and empanelled hospitals. ${ }^{64}$ In fact, contrary to a popular belief that trauma victims face large delays in getting to hospital, many of our frontline stakeholders noted that most severely injured victims in Delhi are already transported rapidly by police. Partly for this reason, they tended to view the taxi-EMS as an additional component to police operations intended for less severely injured victims. Although the use of equipped police 
vehicles to transport trauma victims is unique to Delhi, dispatcher-coordinated police operations are common in many major urban centres in India, ${ }^{65}$ and likely, globally. If these capacities can be extended to emergency transport, they may provide LMICs a cost-effective pathway to coordinated EMS.

Delhi's coordinated police response, as well as our hypothetical taxi-EMS, focus primarily on accidents. However, traumatic injuries only accounts for about onefifth of all emergency health conditions. ${ }^{66}$ Our senior respondents noted that it would be unethical for an EMS to not respond to all health emergencies. Although it is unclear how much the mandate of a police-based operation can be expanded to incorporate other medical services, it may be possible to efficiently link it with other services. Delhi's police already contact the Centralised Accident and Trauma Services public ambulance system, which is often unable to meet demand. However, the supply of ambulances in the EMS could be dramatically increased by including private ambulances, which are commonly available in Delhi but used primarily for inter-hospital transfers. Other governance challenges associated with developing a coordinated system in Delhi include its unique political system (Delhi's governance is shared between the federal government, Delhi's state government and four municipal governments, and the broader National Capital Region includes two other states with their own ambulance systems). Thus, other LMIC settings interested in developing an EMS should assess their current situation of prehospital transport and the availability of existing components of an EMS system that may be integrated and expanded.

Finally, in addition to strengthening prehospital transport, it is important to improve the quality of care provided at hospitals. Consider that recent efforts by the Indian government (including a conditional cash transfer) succeeded in increasing births at facilities but had no effect on maternal and neonatal mortality. ${ }^{67}$ Similarly, Gupta $e t a l^{68}$ describe substantial delays in care for traumatic brain injuries at major trauma facilities in India reducing gains from improving the prehospital system. In summary, improving trauma outcomes in India and LMICs requires understanding how victims access care at present, and developing systems that help victims get quickly to a medical facility where they receive highquality care.

Acknowledgements We are grateful to the many researchers and practitioners who helped us identify relevant documents and connect with stakeholders.

Contributors KB, VS, MV, GT and DM contributed to study conception. KB and VS developed the research protocol. RA, RAr, VS, KB designed interview guides, conducted interviews, coded data and developed preliminary themes. KB and VS refined and finalised themes. KB and VS wrote the first draft of the manuscript. All authors generated hypotheses, interpreted findings and critically reviewed the manuscript.

Funding This work was supported by the US National Institutes of Health (NIH)/ Fogarty (grant number 5R21TW010168).

Competing interests None declared.

Patient consent for publication Not required.
Ethics approval This project was approved by the Institutional Ethics Committees/ Boards of the University of Chicago, St. Stephen's Hospital and Indian Institute of Technology, Delhi.

Provenance and peer review Not commissioned; externally peer reviewed.

Data availability statement No data are available.

Open access This is an open access article distributed in accordance with the Creative Commons Attribution Non Commercial (CC BY-NC 4.0) license, which permits others to distribute, remix, adapt, build upon this work non-commercially, and license their derivative works on different terms, provided the original work is properly cited, appropriate credit is given, any changes made indicated, and the use is non-commercial. See: http://creativecommons.org/licenses/by-nc/4.0/.

\section{ORCID iDs}

Kavi Bhalla http://orcid.org/0000-0002-6679-7820

Veena Sriram http://orcid.org/0000-0001-7235-253X

\section{REFERENCES}

1 Mock C. Strengthening prehospital trauma care in the absence of formal emergency medical services. World J Surg 2009;33:2510-1.

2 Austin S, Murthy S, Wunsch $\mathrm{H}$, et al. Access to urban acute care services in high- vs. middle-income countries: an analysis of seven cities. Intensive Care Med 2014;40:342-52.

3 Mould-Millman N-K, Dixon JM, Sefa N, et al. The state of emergency medical services (EMS) systems in Africa. Prehosp Disaster Med 2017:32:273-83.

4 Roy N, Murlidhar V, Chowdhury R, et al. Where there are no emergency medical services-prehospital care for the injured in Mumbai, India. Prehosp Disaster Med 2010;25:145-51.

5 Das AK, Gupta SB, Joshi SR, et al. White paper on academic emergency medicine in India: Indo-US joint Working Group (JWG). $J$ Assoc Physicians India 2008;56:789-98.

6 Fitzgerald M, Dewan Y, O'Reilly GM, et al. India and the management of road crashes: towards a national trauma system. Indian J Surg 2006;68:226-32.

7 Alagappan K, Cherukuri K, Narang V, et al. Early development of emergency medicine in Chennai (Madras), India. Ann Emerg Med 1998;32:604-8

8 Roudsari BS, Nathens AB, Arreola-Risa C, et al. Emergency medical service (EMS) systems in developed and developing countries. Injury 2007;38:1001-13.

9 Nielsen K, Mock C, Joshipura M, et al. Assessment of the status of prehospital care in 13 low- and middle-income countries. Prehosp Emerg Care 2012;16:381-9.

10. Mock CN, Jurkovich GJ, nii-Amon-Kotei D, et al. Trauma mortality patterns in three nations at different economic levels: implications for global trauma system development. J Trauma 1998;44:804.

11 Solagberu BA, Ofoegbu CKP, Abdur-Rahman LO, et al. Pre-Hospital care in Nigeria: a country without emergency medical services. Niger J Clin Pract 2009;12:29-33.

12 Balhara KS, Bustamante ND, Selvam A, et al. Bystander assistance for trauma victims in low- and middle-income countries: a systematic review of prevalence and training interventions. Prehosp Emerg Care 2019;23:389-410.

13 World Health Organization. Post-Crash response: supporting those affected by road traffic crashes. Geneva: World Health Organization, 2016.

14 World Health Organization. Global status report on road safety 2018. Geneva: World Health Organization, 2018.

15 New Indian Express. Private hospitals cannot say no to emergency victims: CM Kejriwal- The New Indian Express [Internet]. Available: http://www.newindianexpress.com/cities/delhi/2019/jul/31/privatehospitals-cannot-say-no-to-emergency-victims-cm-kejriwal2011914.html [Accessed 28 Aug 2019].

16 Nolan JP, De Latorre FJ, Steen PA, et al. Advanced life support drugs: do they really work? Curr Opin Crit Care 2002;8:212-8.

17 Bickell WH, Wall MJ, Pepe PE, et al. Immediate versus delayed fluid resuscitation for hypotensive patients with penetrating torso injuries. N Engl J Med Overseas Ed 1994;331:1105-9.

18 Kwan I, Mapstone J, Roberts I. Interventions for increasing pedestrian and cyclist visibility for the prevention of death and injuries. Cochrane Database Syst Rev 2002:CD003438.

19 Haut ER, Kalish BT, Efron DT, et al. Spine immobilization in penetrating trauma: more harm than good? J Trauma 2010;68:115-21. 
20 Vanderlan WB, Tew BE, McSwain NE. Increased risk of death with cervical spine immobilisation in penetrating cervical trauma. Injury 2009;40:880-3.

21 Connell RA, Graham CA, Munro PT. Is spinal immobilisation necessary for all patients sustaining isolated penetrating trauma? Injury 2003;34:912-4.

22 Stiell IG, Nesbitt LP, Pickett W, et al. The OPALS major trauma study: impact of advanced life-support on survival and morbidity. CMAJ 2008;178:1141-52.

23 Jayaraman S, Sethi D. Advanced training in trauma life support for ambulance crews. Cochrane Database Syst Rev 2010;20.

24 Liberman M, Mulder D, Sampalis J. Advanced or basic life support for trauma: meta-analysis and critical review of the literature. $J$ Trauma 2000;49:584-99.

25 Sanghavi P. Outcomes after out-of-hospital cardiac arrest treated by basic vs advanced life support, 2014.

26 Sanghavi P, Jena AB, Newhouse JP, et al. Outcomes of basic versus advanced life support for out-of-hospital medical emergencies. Ann Intern Med 2015;163:681-11.

27 Sasser S, Varghese M, Kellermann A, et al. Prehospital trauma care systems. Geneva: World Health Organization, 2005.

28 World Health Organization. Global status report on road safety 2015. Geneva: World Health Organization, 2015.

29 Tiska MA, Adu-Ampofo M, Boakye G, et al. A model of prehospital trauma training for lay persons devised in Africa. Emerg Med $J$ 2004;21:237-9.

30 Geduld H, Wallis L. Taxi driver training in Madagascar: the first step in developing a functioning prehospital emergency care system. Emerg Med J 2011;28:794-6.

31 Murad MK, Husum $\mathrm{H}$. Trained lay first responders reduce trauma mortality: a controlled study of rural trauma in Iraq. Prehosp Disaster Med 2010;25:533-9.

32 Murad MK, Issa DB, Mustafa FM, et al. Prehospital trauma system reduces mortality in severe trauma: a controlled study of road traffic casualties in Iraq. Prehosp Disaster Med 2012;27:36-41.

33 Jayaraman S, Mabweijano JR, Lipnick MS, et al. First things first: effectiveness and scalability of a basic prehospital trauma care program for lay first-responders in Kampala, Uganda. PLoS One 2009;4:e6955

34 Kessler ML, Zhang Y. Transportation network companies: what does the future hold? 2019.

35 Rathor S. Continental Hospitals: Uber partners with Continental Hospitals and Call Ambulance for drivers' training. In: Times of India [Internet], 2016. Available: https://timesofindia.indiatimes. com/city/hyderabad/Uber-partners-with-Continental-Hospitalsand-Call-Ambulance-for-drivers-training/articleshow/54786044.cms [Accessed 25 May 2019].

36 Reporter S. Taxi ambulance service launched. The Hindu, 2018. Available: https://www.thehindu.com/news/cities/Delhi/taxiambulance-service-launched/article24334207.ece [Accessed 25 May 2019]

37 Behal A. AMBER Health Sets Out To Be The Uber Of India's Medical Emergency Response System. In: Forbes [Internet], 2016. Available: https://www.forbes.com/sites/abehal/2016/03/23/amber-healthsets-out-to-be-the-uber-of-indias-medical-emergency-responsesystem/\#49e123df79bb [Accessed 25 May 2019].

38 Seetharaman G. World Health Organisation: How a bunch of startups are trying to make life easier for those in need of an ambulance. In: Economic Times [Internet], 2017. Available: https:// economictimes.indiatimes.com/small-biz/startups/how-a-bunchof-startups-are-trying-to-make-life-easier-for-those-in-need-of-anambulance/articleshow/59716071.cms [Accessed 17 Aug 2019].

39 The Intersection of Governments in Delhi [Internet]. Cities of Delhi, centre for policy research India, 2015. Available: citiesofdelhi. cprindia.org

40 Centralised Accident and Trauma Services: CATS. Government of National Capital Territory of Delhi [Internet]. Available: http://dceast. delhigovt.nic.in/wps/wcm/connect/doit_cats/CATS/Home/History [Accessed 17 Aug 2019].

41 Sankar J, Singh A, Narsaria P, et al. Prehospital transport practices prevalent among patients presenting to the pediatric emergency of a tertiary care hospital. Indian J Crit Care Med 2015;19:474-8.

42 Roy N. Towards improved trauma care outcomes in India. Stockholm, Sweden: Department of Public Health Sciences, Karolinska Institutet, 2017.
43 Reddy KS. India's aspirations for universal health coverage. N Engl $J$ Med 2015;373:1-5.

44 Ramakrishnan N, Ranganathan L, Abraham BK, et al. What happens to patients discharged against medical advice? Indian J Crit Care Med 2018;22:580-4.

45 Naderi S, Acerra JR, Bailey K, et al. Patients in a private hospital in India leave the emergency department against medical advice for financial reasons. Int J Emerg Med 2014;7:13.

46 Pallavisarji U, Gururaj G, Girish RN. Practice and perception of first aid among lay first responders in a southern district of India. Arch Trauma Res 2013;1:155-60.

47 Save Life Foundation. Study on impediments to bystander care in India. New Delhi: SaveLIFE Foundation, 2013.

48 Gowda G V, Mishra A. Savelife Foundation \& Anr vs Union Of India \& Anr on 30 March, 2016, 2016. Available: https://indiankanoon.org/ doc/79865001/

49 Ministry of Road Transport and Highways. Notification: regarding protection of good samaritans. The Gazette of India, 2015: 25035/101/2014-RS.

50 Patton M. Qualitative evaluation and research methods. Beverly Hills, CA: Sage, 1990.

51 Braun V, Clarke V. Using thematic analysis in psychology. Qual Res Psychol 2006;3:77-101.

52 Reddy KS. Health care reforms in India. JAMA 2018;319.

53 The motor vehicles Amendment bill, 2019. 154-C of 2019 Jul 23 2019.

54 Government of Delhi. Office memorandum regarding guidelines for cashless treatment of medico-legal victims.

55 Withnall A. "Good Samaritans" are still being arrested for helping accident victims in India. The Independent, 2018. Available: https:// www.independent.co.uk/news/world/asia/india-traffic-accidentsgood-samaritans-help-arrested-harassed-police-a8654096.html [Accessed 25 May 2019].

56 Dutt A. Cops better than good samaritans on Delhi streets, shows data, 2019. Available: https://www.hindustantimes.com/delhinews/cops-better-than-good-samaritans-on-delhi-streets-showsdata/story-IZX8FmQAB0g5WNLCdmd1TN.html [Accessed 25 May 2019].

57 Banerjee AV, Chattopadhyay R, Duflo E, et al. Can institutions be reformed from within? Evidence from a randomized experiment with the Rajasthan police. SSRN Journal 2012.

58 Pardun JT. Good Samaritan laws: a global perspective. Loy LA Int'l \& Comp L Rev 1998;20.

59 Brandt EA. Good Samaritan Laws - The Legal Placebo: A Current Analysis. Akron Law Review 1983;17:32.

60 Clarke D. China does not need a good Samaritan law. in: the China collection, 2017. Available: https://thechinacollection.org/china-notneed-good-samaritan-law/ [Accessed 19 May 2019].

61 Clarke D. Chinese Law Prof Blog: Random comments on China's new civil code [Internet], 2017. Available: https://lawprofessors. typepad.com/china_law_prof_blog/2017/03/random-comments-onchinas-new-civil-code.html [Accessed 19 May 2019].

62 Parliament of the Republic of India. The Motor Vehicles Act, 1988 [Internet], 1988. Available: https://indiankanoon.org/doc/785258/

63 Schmets G, Rajan D, Kadandale S. Strategizing National health in the 21st century: a Handbook. Geneva, Switzerland: World Health Organization, 2016.

64 Sengupta R. What happens when you dial 100? 2017. Available: https://www.livemint.com/Politics/lvTuSzxCnrrHH8RmlpZ6hP/Whathappens-when-you-dial-100.html [Accessed 15 Aug 2019].

65 Manglam A. Centralized emergency police response system. Bureau of police research and development, Ministry of home Affairs. Government of India, 2018.

66 Razzak J, Usmani MF, Bhutta ZA. Global, regional and national burden of emergency medical diseases using specific emergency disease indicators: analysis of the 2015 global burden of disease study. BMJ Glob Health 2019;4:e000733.

67 Patel AB, Prakash AA, Raynes-Greenow C, et al. Description of Inter-Institutional referrals after admission for labor and delivery: a prospective population based cohort study in rural Maharashtra, India. BMC Health Serv Res 2017;17:360.

68 Gupta S, Khajanchi M, Kumar V, et al. Third delay in traumatic brain injury: time to management as a predictor of mortality. $J$ Neurosurg 2019;1:1-7. 